\title{
Wenn Gesundbeten wirkt, müsste auch Verwünschen wirken
}

In unserem Schwerpunkt „Religion und Gesundheit" in MMW Nr. 51-51/2007, S. 30 ff. wurde auch die Clearwater-Studie zitiert, in der eine Wirkung des Gebetes bei Arthritis nachgewiesen werden sollte. Keine sehr überzeugende Studie, wie ein Leser meint:

— In der Clearwater-Studie wurden anstelle eines Endpunktes zehn Variablen bei unterpowerter Teilnehmerzahl (26 versus 14) getestet. Daten und Instrumente der Clearwater-Mikrostudie sind nicht geeignet, um induzierbare Schlussfolgerungen abzuleiten.

Will man an die Wirkung von Gebeten im Diesseits aufzeigen, so ist umgekehrt die Wirksamkeit des Verwünschens nachzuweisen. Magischanimistische Vorstellungen sind auch nach der Zeit der Aufklärung verbreitete Muster des Denkens. Die Bereit- schaft des Menschen für einen behaupteten Glauben, Humanität und Recht, Verantwortung und Beweis beiseite zu schieben, entspringt diesem magischen Denken, das religionsfern ist.

- Dr. med. Martin P. Wedig, Roonstraße 86,
D-44628 Herne
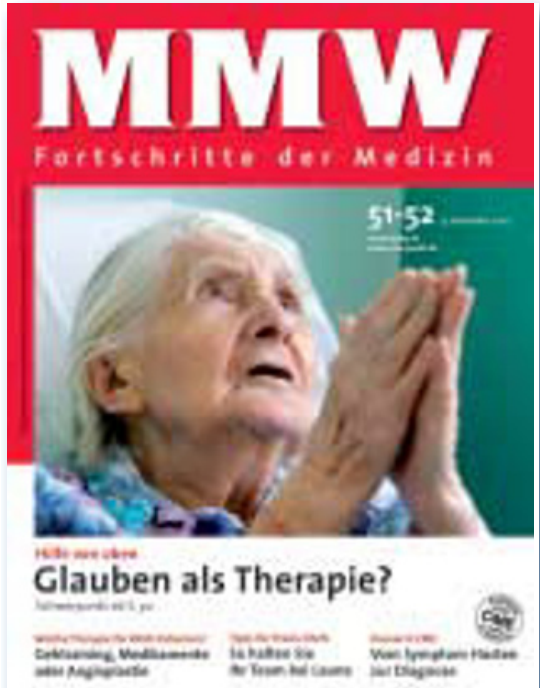

\section{Ich teile die Verantwortung gern mit dem lieben Gott}

- Wenn ich als Therapeut zugebe, dass das Gebet sehr hilfreich, sogar machtvoll (vgl. den Geistheiler Harry Edwards) sein kann, bin ich nicht mehr der/die Allmächtige. Wer entmachtet sich selber schon gerne? Trotzdem kann ich für mich sagen, dass es eine sehr große Entlastung für den Therapeuten bedeutet, wenn er in der Lage ist, die Verantwortung für das Gesundwerden des Patienten mit dem lieben Gott zu teilen.

- Eva Balster De Beer, per E-Mail

\section{MMW-Leserbefragung}

\section{Sie haben gewonnen!}

— In MMW Nr. 48/2007, S. 4 haben wir Sie gebeten, uns Ihre Meinung über die MMW mitzuteilen. Über die rege Teilnahme und die vielen Anregungen, die Sie uns gegeben haben, haben wir uns sehr gefreut. Ihre Ideen, wie wir die MMW noch lesbarer und noch praxisrelevanter gestalten können, waren nicht in den Wind gesprochen. Wir nehmen Ihre Anregungen sehr Ernst und versu-

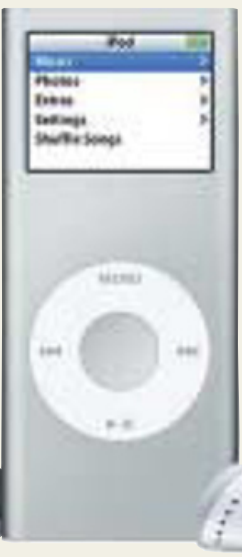

chen unser Bestes, sie in die Tat umzusetzen.

Damit haben eigentlich alle gewonnen, wir in unserer täglichen Redaktionsarbeit und Sie als unsere treuen Leser. Aber wir haben ja auch ein paar handfestere Preise ausgelobt. Und darüber dürfen sich folgende Leser freuen:

Frau Dr. med. Sabine

Bank, Fachärztin für Allgemeinmedizin in Schwerin ist unsere Hauptgewinnerin. Herzlichen Glück-

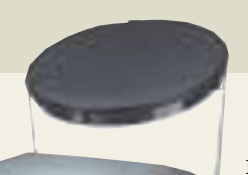

wunsch $\mathrm{zu}$ Ihrem neuen I-Pod!

Über je eine Kaffeemaschine "Tassimo" von Braun dürfen sich Frau Dr. med. Margret Schindler-Gloe in $\mathrm{T} \ddot{\mathrm{u}} \mathrm{b}$ i $\mathrm{n}$ g e $\mathrm{n}$ und Frau Dr. med. Cornelia Fournell in Düsseldorf freuen. Herzlichen Glückwunsch! 